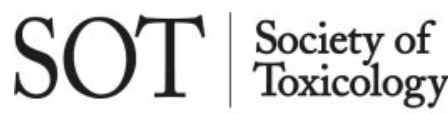

www.toxsci.oxfordjournals.org

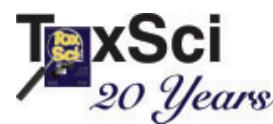

doi: $10.1093 /$ toxsci/kfy068

Advance Access Publication Date: March 21, 2018

Research Article

\title{
Metabolic and Phenotypic Characterization of Human Skin Fibroblasts After Forcing Oxidative Capacity
}

\author{
Susana P. Pereira, ${ }^{*, 1}$ Cláudia M. Deus, ${ }^{*, \dagger}$ Teresa L. Serafim, ${ }^{*, 2}$ \\ Teresa Cunha-Oliveira, ${ }^{*}$ and Paulo J. Oliveira*,+,3
}

${ }^{*} \mathrm{CNC}$-Center for Neuroscience and Cell Biology, University of Coimbra, UC Biotech Building, Biocant Park, 3060-197 Cantanhede, Portugal; and ${ }^{\dagger} I I I U C$-Institute for Interdisciplinary Research, University of Coimbra, 3030-789 Coimbra, Portugal

\footnotetext{
${ }^{1}$ Present address: The Research Centre in Physical Activity, Health and Leisure (CIAFEL), Faculty of Sports, University of Porto, $4200-450$ Porto, Portugal.

${ }^{2}$ Present address: iMM—Instituto de Medicina Molecular, University of Lisbon, 1649-028 Lisboa, Portugal.

${ }^{3}$ To whom correspondence should be addressed at CNC-Center for Neuroscience and Cell Biology, University of Coimbra, UC Biotech Building (Lot 8A),
} Biocant Park, 3060-197 Cantanhede, Portugal. Fax: +351-231-249-179. E-mail: pauloliv@cnc.uc.pt.

\begin{abstract}
Human skin fibroblasts present technical advantages for the study of mitochondrial-induced toxicity, because those cells can be isolated from patients by lowly invasive methods and present specific cumulative cellular damage and mutations of particular conditions. Several drugs lead to organ toxicity, with some of these drugs having been already withdrawn from the market. Frequently, drug-induced toxicity is attributed to mitochondrial liabilities. One of the approaches to identify drug-induced mitochondrial toxicity is using glucose-free/galactose/glutamine/pyruvate-containing cell culture media that force cells to be more dependent on oxidative phosphorylation for energy production. However, the effects of this modified culture medium itself on the mitochondrial phenotype of human skin fibroblasts have not been explored in detail. Our objective was to assess the mitochondrial biology of human skin fibroblasts under standard or modified culture conditions so that system can be validated and used in a more reliable way to disclose mitochondrial liabilities of drug candidates or intrinsic metabolic differences in fibroblasts. Our results showed that forcing mitochondrial remodeling in human skin fibroblasts increased oxygen consumption rate, ATP levels, and mitochondria-related transcripts and proteins. Moreover, the metabolic remodeling increased cytotoxicity of mitochondrial poisons. In general, no alterations in gene expression related with differentiation status were observed in human skin fibroblasts, with exception of increased paxilin gene expression. Not only the current work highlights the importance of using human skin primary cells to study drug-induced mitochondrial toxicity, it also reinforces the use of this tool to detect specific mitochondrial defects in skin fibroblasts from patients.
\end{abstract}

Key words: skin fibroblasts; metabolism; personalized medicine; toxicity; mitochondria.

Human skin fibroblasts have been used to explore mechanisms involved in the pathophysiology of several diseases, such as Parkinson's disease (Ambrosi et al., 2014), Alzheimer's disease (Hu et al., 2015), and Leigh syndrome (Cameron et al., 2004), specially due to cells' easy availability, robustness, and physiologically relevant metabolism (Auburger et al., 2012; Marroquin et al., 2007). Moreover, skin fibroblasts can be isolated from patients by minimally invasive methods and they reflect cumulative cell damage and (mt)DNA polymorphisms and mutations (Auburger et al., 2012), which might be a valid tool for basic research and drug development.

A large number of drugs have treatment-related side effects that cause injury to the liver, heart, skeletal muscles, kidneys, and nervous system, with some of these drugs being withdrawn from the market (Marroquin et al., 2007; Swiss and Will, 2011). Normally, drug-induced toxicity is idiosyncratic and side effects 
are attributed to detrimental effects in mitochondrial function, which in the majority of the cases are not detected during preclinical phase studies (Marroquin et al., 2007). Mitochondria are considered the powerhouses of the cell, because they enclose important energy-producing metabolic pathways (Pereira et al., 2009; Picard et al., 2016). Besides ATP production, mitochondria display other important roles, including intracellular calcium $\left(\mathrm{Ca}^{2+}\right)$ regulation (Arduino et al., 2017), as well as redox and apoptotic signaling pathways (Smith et al., 2012; Teixeira et al., 2017). Decline in mitochondrial function has been associated with a wide range of human pathologies (Wallace et al., 2010), while alterations caused by drug toxicity have been extensively demonstrated (Marroquin et al., 2007; Masubuchi et al., 2006; Ong et al., 2007; Swiss and Will, 2011; Tirmenstein et al., 2002). For example, troglitazone, a thiazolidinedione antidiabetic agent, which was already withdrawn from the market, was shown to decrease mitochondrial membrane potential, induce mitochondrial $\mathrm{Ca}^{2+}$ accumulation and mitochondrial permeability transition (MPT) pore, and alter mitochondrial redox signaling leading to hepatotoxicity (Masubuchi et al., 2006; Ong et al., 2007). Furthermore, statins, a class of lipid-lowering medication, inhibit ubiquinone biosynthesis impacting mitochondrial metabolism by disrupting electron transport chain in muscle mitochondria (Schaefer et al., 2004). Another example is doxorubicin, a chemotherapeutic cardiotoxic drug, which was demonstrated to increase mitochondrial ROS production, ATP depletion, MPT pore formation, and cause mitochondrial membrane potential disruption and apoptotic signaling (Carvalho et al., 2014; Deus et al., 2015; Pereira et al., 2016). Several approaches have been used to disclose drug-induced mitochondrial toxicity in pre-clinical assays. Marroquin et al. (2007) used a glucose-free/galactose/glutamine/pyruvate-containing culture medium to force cells to use oxidative phosphorylation (OXPHOS) for ATP production exposing the drug-induced mitochondrial toxicity, which is now used by many research groups. However, the effects of this modified culture medium in terms of mitochondrial phenotype, differentiation status, and gene expression in fibroblasts are not well characterized. Moreover, the majority of studies were performed using tumor-derived immortalized cell lines, such as the hepatocellular tumor HepG2 cell line (Marroquin et al., 2007; Tirmenstein et al., 2002), down-playing the relevance of human skin fibroblasts as a more reliable tool to study mitochondrial drug-induced toxicity. Based on that, our general objective was to validate the cell model composed by human skin fibroblasts under standard culture conditions versus the modified culture media used to disclose mitochondrial liabilities of drug candidates or metabolic differences in skin fibroblasts from donors. Specifically, by using different culture conditions, our aims were to (1) characterize mitochondrial bioenergetics alterations, protein and gene expression induced by mitochondrial remodeling in human skin fibroblasts, (2) evaluate the susceptibility of human skin fibroblasts to mitochondrial poisons, and c) evaluate whether mitochondrial remodeling alters the differentiation status of human skin fibroblasts. We demonstrated here that by using the modified culture media, mitochondrial oxidative capacity was increased, concomitantly with alterations at the transcriptional level of mitochondrial proteins relevant to OXPHOS. Remarkably, modulation of skin fibroblasts metabolism caused minimal alterations on cell differentiation markers. Our study is the first comprehensive analysis of the changes that occur in mitochondrial function and structure in a human skin fibroblast cell line, highlighting not only the importance of using human skin primary cells to study drug-induced mitochondrial toxicity as well as the possibility to use this tool to detect particular mitochondrial defects in human fibroblasts from patients.

\section{MATERIALS AND METHODS}

\section{Reagents}

Bovine serum albumin (BSA), ammonium persulfate (APS), Bradford reagent, brilliant blue $\mathrm{G}$, calcium chloride $\left(\mathrm{CaCl}_{2}\right)$, dimethyl sulfoxide (DMSO), DL-dithiothreitol (DTT), ethylenediaminetetraacetic acid (EDTA), glycerol, glycine, $\beta$-mercaptoethanol 98\%, phenylmethylsulfonyl fluoride (PMSF), sodium chloride $(\mathrm{NaCl})$, sodium dodecyl sulfate (SDS), sulforhodamine B (SRB) sodium salt, trizma base and trypan-blue solution were obtained from Sigma-Aldrich (Barcelona, Spain). Acetic acid, ethanol, hydrochloric acid $(\mathrm{HCl})$, magnesium chloride $\left(\mathrm{MgCl}_{2}\right)$, methanol, potassium chloride $(\mathrm{KCl})$, potassium phosphate monobasic $\left(\mathrm{KH}_{2} \mathrm{PO}_{4}\right)$, sodium hydrogencarbonate $\left(\mathrm{NaHCO}_{3}\right)$, sodium sulfate $\left(\mathrm{NaSO}_{4}\right)$ and sodium hydroxide $(\mathrm{NaOH})$ were also obtained from Merck (Whitehouse Station, NJ, USA). Acrylamide, Laemmli buffer, Tris $\mathrm{pH}$ 8.8, Tris $\mathrm{pH}$ 6.8, PVDF membranes and $\mathrm{N}, \mathrm{N}, \mathrm{N}^{\prime}, \mathrm{N}^{\prime}$-tetramethylethylenediamine (TEMED) were obtained from BioRad (Hercules, CA, USA). The ECF detection system was obtained from GE Healthcare Life Sciences (Buckinghamshire, UK). The fluorescent probe tetramethyl rhodaminemethylester (TMRM) was obtained from Molecular Probes (Eugene, OR, USA). Dulbecco's modified Eagle's medium without glucose (DMEM, 5030), penicillin, streptomycin, fetal bovine serum (FBS), and $0.25 \%$ Trypsin-EDTA were purchased from Gibco-Invitrogen (Grand Island, NY, USA). Cell lysis buffer (9803) was obtained from Cell Signaling Technology (Danvers, MA, USA).

All reagents and chemical compounds used were of the greatest degree of purity commercially available. In the preparation of aqueous solutions, ultrapure distilled water (conductivity $<18 \mu \mathrm{S} / \mathrm{cm}$ ), filtered by a Milli Q Millipore system, was used in order to minimize as much as possible contamination with metal ions. For non-aqueous solutions, ethanol $(95 \%$, Sigma-Aldrich) was use as solvent.

\section{Cell Culture}

Human skin fibroblast cell line, BJ (CRL-2522, ATCC, UK) was cultured in DMEM (D5030) supplemented with $4.5 \mathrm{~g} / \mathrm{l}$ glucose ( $25 \mathrm{mM}$ final concentration), $1.8 \mathrm{~g} / \mathrm{l}$ sodium bicarbonate, $0.11 \mathrm{~g} / \mathrm{L}$ sodium pyruvate, and $10 \%$ fetal bovine serum in $100-\mathrm{cm}^{2}$ cell culture dishes at $37^{\circ} \mathrm{C}$ in a humidified atmosphere of $5 \% \mathrm{CO}_{2}$. This medium is here referred as "high glucose medium" (HGm). Another group of cells was adapted for at least 5 passages in a modified glucose-free culture media (DMEM, 5030) supplemented with $1.8 \mathrm{~g} / 1$ sodium bicarbonate, $0.11 \mathrm{~g} / 1$ sodium pyruvate, $1.8 \mathrm{~g} / \mathrm{l}$ galactose, $0.584 \mathrm{~g} / \mathrm{l} \mathrm{L}$-glutamine, and $10 \%$ fetal bovine serum according with Marroquin et al. (2007) and cells cultured in the same conditions described before. This culture medium was used to force the cells to preferably use OXPHOS for ATP production (Marroquin et al., 2007) and is referred here as OXPHOS medium (OXPHOSm). Cells were passaged by trypsinization with $0.05 \%$ trypsin-EDTA using standard methods when reaching $70 \%-80 \%$ confluence and all experiments were performed from cultures in log-phase growth. Stock solution of rotenone, FCCP, and oligomycin were prepared in ethanol and stored frozen. Vehicle controls received an equivalent amount of ethanol, which never exceeded $0.1 \% \mathrm{v} / \mathrm{v}$. 


\section{Cell Proliferation Measurement}

The SRB assay was used to determine cellular mass and estimate proliferation, as well as to measure the loss of cell mass consequent from the mitochondrial poisons cytotoxicity. For cell proliferation studies, cells were seeded at a concentration of 2500, 5000, 10 000, 20 000, 40000 cells/ $\mathrm{cm}^{2}$ in 48-well plates, with a final volume of $500 \mu \mathrm{l}$ per well and allowed to proliferate during $24,48,72,96,120$, and $144 \mathrm{~h}$. Growth media was replaced every 2 days. For cytotoxicity study cells were seeded at a concentration of 40000 cells $/ \mathrm{cm}^{2}$ and were incubated with $1,2,4$, and $10 \mu \mathrm{M}$ of rotenone, FCCP, and oligomycin during 6,24 , and $48 \mathrm{~h}$. In the controls the equivalent amount of ethanol was added. At specific time points, the incubation medium was removed, and cells were fixed in $1 \%$ acetic acid in ice-cold methanol for at least 1 day. Cells were then incubated with $0.05 \%(w / v)$ $\mathrm{SRB}$ reagent dissolved in $1 \%$ acetic acid for $1 \mathrm{~h}$ at $37^{\circ} \mathrm{C}$. Unbound dye was removed with $1 \%$ acetic acid. Dye bound to cell proteins was extracted with $10 \mathrm{mM}$ Tris-base solution, $\mathrm{pH}$ 10. After SRB labeling, absorbance was measured in a Biotek Cytation 3 spectrophotometer at $510 \mathrm{~nm}$ with background correction at $620 \mathrm{~nm}$, the amount of dye released is proportional to the number of cell mass in each well, as demonstrated previously (Silva et al., 2016; Vichai and Kirtikara, 2006).

\section{Metabolic Activity Determination}

The resazurin assay was used to measure the cellular viability based on metabolic activity of living cells through the fluorescence intensity of formed resorufin. Cells were seeded at a concentration of 40000 cells $/ \mathrm{cm}^{2}$ in 48 -well plates, with a final volume of $500 \mu \mathrm{l}$ per well. Resazurin stock solution $(1 \mathrm{mg} / \mathrm{ml})$ was prepared in PBS $1 \times$ and stored at $-20^{\circ} \mathrm{C}$. For each cell growth time point, $24,48,72,96,120$, and $144 \mathrm{~h}$ cell media from each well was cautiously removed and cells were carefully washed with PBS $1 \times$. After removing the PBS $1 \times, 500 \mu$ l of resazurin solution (1:1000 dilution in growth medium from a stock solution) was added in each well and incubated for $6 \mathrm{~h}$ at $37^{\circ} \mathrm{C}$ with a $5 \% \mathrm{CO}_{2}$ atmosphere. Resorufin fluorescence was measured in a Biotek Cytation 3 spectrophotometer using excitation wavelength of $540 \mathrm{~nm}$ and emission of $590 \mathrm{~nm}$ (Silva et al., 2016).

\section{Vital Epifluorescence Microscopy Characterization}

Vital epifluorescence microscopy was used to detect alterations in mitochondrial polarization and network distribution in human skin fibroblasts. Cells were seeded in 6 well-plates with a glass coverslip per well with a final volume of $2 \mathrm{ml}$ per well. After $24 \mathrm{~h}$, cells were incubated during $30 \mathrm{~min}$ with nonquenching concentrations of the fluorescent dye TMRM $(100 \mathrm{nM})$ in microscopy solution buffer $(120 \mathrm{mM} \mathrm{NaCl}, 3.5 \mathrm{mM} \mathrm{KCl}, 0.4 \mathrm{mM}$ $\mathrm{KH}_{2} \mathrm{PO}_{4}, 20 \mathrm{mM}$ HEPES, $5 \mathrm{mM} \mathrm{NaHCO} 3,1.2 \mathrm{mM} \mathrm{Na}_{2} \mathrm{SO}_{4}$, and $10 \mathrm{mM}$ sodium pyruvate) supplemented with $1.2 \mathrm{mM} \mathrm{MgCl}_{2}$ and $1.3 \mathrm{mM} \mathrm{CaCl}_{2}$. Then, cells were washed with microscopy solution buffer. Images were obtained using a Nikon Eclipse TE2000U microscope and were analyzed with ImageJ $1.45 \mathrm{~S}$ program.

\section{Intracellular Adenine Nucleotides Measurement}

For the evaluation of intracellular adenine nucleotides pool, the media was removed and cells were collected in perchloric acid solution. The suspension was then centrifuged, and the supernatant recovered. The supernatant, containing adenine nucleotides, was neutralized and analyzed by reverse-phase high performance liquid chromatography for quantification of the adenine nucleotides. The chromatographic apparatus was a Beckman-System Gold (Beckman Coulter, Fullerton, CA, USA), consisting of a 126 Binary Pump Model and a 166 Variable UV detector, computer controlled. Detection was performed by an ultraviolet detector at $254 \mathrm{~nm}$ and the column was a Lichrospher 100RP-18 (5 $\mu \mathrm{m})$ from Merck (Darmstadt, Germany). Samples were eluted with $100 \mathrm{mM}$ phosphate buffer $\left(\mathrm{KH}_{2} \mathrm{PO}_{4}\right)$, $\mathrm{pH} 6.5$, and $1 \%$ methanol with a flow rate of $1.1 \mathrm{ml} / \mathrm{min}$. Pellet protein concentration was determined after the addition of $1 \mathrm{M}$ $\mathrm{NaOH}$, by using the Bradford assay, with BSA as a standard (Bradford, 1976). Energy charge was calculated as ([ATP] +0.5 $[\mathrm{ADP}]) /([\mathrm{ATP}]+[\mathrm{ADP}]+[\mathrm{AMP}])$.

\section{Cellular Oxygen Consumption Quantification}

Oxygen consumption was measured at $37^{\circ} \mathrm{C}$ using a Seahorse $\mathrm{XF}^{\mathrm{e}} 96$ Extracellular Flux Analyzer (Agilent Technologies, Santa Clara, CA, USA). Cells were seeded under the same conditions described above at a density of 80000 cells $/ \mathrm{cm}^{2}$ because the absolute rate of oxygen consumption was linearly related to the cell number between 30000 and 100000 cells/well. A XFe96 sensor cartridge for each cell plate was placed in a 96-well calibration plate containing $200 \mu \mathrm{l} /$ well calibration buffer and left to hydrate overnight at $37^{\circ} \mathrm{C}$. The cell culture medium from the plates was replaced the following day with $180 \mu \mathrm{l} /$ well of prewarmed low-buffered serum-free minimal DMEM (D5030, Sigma-Aldrich) medium, the $\mathrm{pH}$ adjusted to 7.4 and incubated at $37^{\circ} \mathrm{C}$ for $1 \mathrm{~h}$ to allow the temperature, and $\mathrm{pH}$ of the medium to reach equilibrium before the first measurement. Oligomycin, FCCP, rotenone, and antimycin A were prepared in DMSO. For oxygen consumption rate (OCR) measurements, $3 \mu \mathrm{M}$ oligomycin, injected into reagent delivery port A was diluted in lowbuffered serum-free DMEM medium and the $\mathrm{pH}$ adjusted to 7.4 with $1 \mathrm{M} \mathrm{NaOH}$. Following the addition of oligomycin, $2 \mu \mathrm{M}$ FCCP (previously optimized concentration) was injected into port B. The port $C$ was loaded with $2.5 \mu \mathrm{M}$ rotenone plus $2.5 \mu \mathrm{M}$ antimycin diluted in low-buffered serum-free DMEM medium and the $\mathrm{pH}$ adjusted to 7.4 with $1 \mathrm{M} \mathrm{NaOH}$. The ports were sequentially loaded with 20,22 , and $24 \mu$ l of compounds, respectively in the $\mathrm{XF}^{\mathrm{e}} 96$ sensor cartridge. The sensor cartridge and the calibration plate were loaded into the $\mathrm{XF}^{\mathrm{e}} 96$ Extracellular Flux Analyzer for calibration. The calibration plate was then replaced with the study plate. Three baseline rate measurements of BJ cell line OCR were made using a $3 \mathrm{~min} \mathrm{mix}, 5 \mathrm{~min}$ measure cycle. The compounds were then pneumatically injected into each well and mixed with OCR measurements made using a $3 \mathrm{~min}$ mix, 5 min measure cycle. Results were normalized to cell mass and analyzed by using the Software Version Wave Desktop 2.2 (Agilent Technologies, Santa Clara, CA, USA).

\section{Protein Semi-Quantification by Western Blot}

To obtain total cellular extracts, total cell pool was harvested by trypsinization and washed once with PBS $1 \times$. In order to collect the cells, two centrifugation steps were performed for $5 \mathrm{~min}$ at $1000 \times \mathrm{g}\left(4^{\circ} \mathrm{C}\right)$. The cellular pellet was resuspended in cell lysis buffer $1 \times$ (Bio-Rad, Hercules, CA, USA, 9803) supplemented with $100 \mu \mathrm{M}$ PMSF. Protein content was determined by the Bradford method using BSA as a standard (Bradford, 1976). An equivalent amount of protein $(20 \mu \mathrm{g})$ for each sample was separated by electrophoresis on 12 SDS-polyacrylamide gel (SDS-PAGE) and electrophoretically transferred to a polyvinylidene fluoride (PVDF) membrane. The membranes were stained with Ponceau $\mathrm{S}$ solution (Sigma-Aldrich, Barcelona, Spain), an accurate method to confirm equal protein load (Romero-Calvo et al., 2010), to confirm equivalent protein loading in each lane. After blocking with $5 \%$ milk in TBST $(50 \mathrm{mM}$ Tris- $\mathrm{HCl}, \mathrm{pH} 8 ; 154 \mathrm{mM}$ $\mathrm{NaCl}$ and $0.1 \%$ tween 20 ) for $2 \mathrm{~h}$ at room temperature, PVDF 
membranes were incubated overnight at $4^{\circ} \mathrm{C}$ with primary antibodies to semi-quantify subunits from OXPHOS system (1:1000; ab110304, Abcam) and mitochondrial membrane carriers and translocators (1:1000; ab110414, Abcam), peroxisome proliferator-activated receptor gamma coactivator 1-alpha (PGC1- $\alpha)$ (1:750, ST1202, Millipore), citrate synthase (1:1000, ab96600, Abcam), and mitochondrial translocase of outer membrane subunit 20 (TOM20) (1:1000, ab56783, Abcam). Membranes were further incubated with the correspondent alkaline phosphatase conjugated secondary antibody, goat anti-mouse IgG (1:2500) or goat anti-rabbit IgG (1:2500), for $1 \mathrm{~h}$ at room temperature. Membranes were then incubated with the ECF detection system (GE Healthcare, Piscataway, NJ, USA) and imaged with a Biospectrum-Multispectral imaging system (UVP; LLC Upland, CA; Cambridge, UK). The densities of each band were calculated with Image $1.45 \mathrm{~S}$ program. First, we converted the images to a grayscale, to show protein bands as black pixels. Then, authors selected the region of interest (ROI) for each band and integrated density was measured. The ROI area was kept constant for all bands.

\section{Calculation of mtDNA Copy Number}

Cells were collected and centrifuged at $2000 \times \mathrm{g}$ for $5 \mathrm{~min}$. The pellets were washed in $5 \mathrm{~mL}$ of PBS $1 \times$ and the suspension was centrifuged at $2000 \times \mathrm{g}$ for $5 \mathrm{~min}$. The resulting pellets were stored at $-80^{\circ} \mathrm{C}$ until total DNA extraction. Total DNA was extracted from cell pellets using the PureLink Genomic DNA Mini Kit (K1820-01, Life Technologies, Carlsbad, CA, USA), following the manufacturer's protocols and quantified using a Nanodrop 2000 (Thermo Scientific, Waltham, MA, USA). RT-PCR was performed using the SsoFast Eva Green Supermix, in a CFX96 real-time PCR system (Bio-Rad, Hercules, CA, USA), with the primers described in Table 1 , at $500 \mathrm{nM}$. Amplification of $25 \mathrm{ng}$ total DNA was performed with an initial cycle of $2 \mathrm{~min}$ at $95^{\circ} \mathrm{C}$, followed by 40 cycles of $5 \mathrm{~s}$ at $95^{\circ} \mathrm{C}$ plus $20 \mathrm{~s}$ at $63^{\circ} \mathrm{C}$, and $20 \mathrm{~s}$ at $72^{\circ} \mathrm{C}$. At the end of each cycle, Eva Green fluorescence was recorded to enable determination of Cq. For quality control, after amplification, melting temperature of the PCR products was determined by performing melting curves. For each set of primers, amplification efficiency was assessed, and no template controls were run. mtDNA copy number was determined in each sample by the ratio between the amount of a fragment of the mtDNA control region (Mito3) and the amount of the RNAseP nuclear gene, using the CFX96 Manager software (v. 3.0; Bio-Rad, Hercules, CA, USA).

\section{Gene Expression Assessment}

Total RNA was extracted with RNeasy mini-kit (Qiagen, Düsseldorf, Germany), following the manufacturer's protocols, and quantified using a Nanodrop 2000 (Thermo Scientific, Waltham, MA, USA), confirming that A260/280 was higher than 1.9. RNA integrity was verified by Experion RNA StdSens kit (Bio-Rad, Hercules, CA, USA), and RNA was converted into cDNA using the NZY first-strand cDNA synthesis kit (NZYTech, Lisbon, Portugal), following the manufacturer's instructions. RT-PCR was performed using the SsoFast Eva Green Supermix, in a CFX96 real-time PCR system (Bio-Rad, Hercules, CA, USA), with the primers defined in Table 1, at $500 \mathrm{nM}$. Amplification of $25 \mathrm{ng}$ was performed with an initial cycle of $30 \mathrm{~s}$ at $95^{\circ} \mathrm{C}$, followed by 40 cycles of $5 \mathrm{~s}$ at $95^{\circ} \mathrm{C}$ plus $5 \mathrm{~s}$ at $60^{\circ} \mathrm{C}$. At the end of each cycle, Eva Green fluorescence was recorded to enable determination of Cq. After amplification, melting temperature of the PCR products were determined by performing melting curves and amplicon length was confirmed by agarose electrophoresis. For each set of primers, amplification efficiency was assessed, and no template and no transcriptase controls were run. Relative normalized expression was determined by the CFX96 Manager software (v. 3.0; Bio-Rad), using 18S RNA as reference gene.

\section{Statistical Analysis}

Data were analyzed with GraphPad Prism 6.01 (GraphPad Software, Inc. San Diego, CA) and presented as mean \pm standard error of the mean (SEM) for the number of experiments indicated in the legends of the figures. Data normality was tested with Kolmogorov-Smirnov and Shapiro-Wilk test. Statistical analysis of two groups was performed using the nonparametric Mann-Whitney test or one-way analysis of variance (ANOVA) followed by Sidak post hoc test for comparing different mitochondrial poisons concentrations. Values with $p<.05$ were considered as statistically significant $(*)$.

\section{RESULTS}

\section{Mitochondrial Remodeling of Human Skin Fibroblast Cell Line} Increased Oxygen Consumption Rate and ATP Levels

Because human skin fibroblasts represent a valid tool to study different pathologies (Ambrosi et al., 2014; Cameron et al., 2004; Hu et al., 2015) due to its physiologically relevant metabolism, availability and robustness (Auburger et al., 2012; Marroquin et al., 2007), we initially characterized the phenotype of human skin BJ fibroblasts when cultured in OXPHOSm, which forces cells to use OXPHOS for ATP production, or in the commonly used HGm (Marroquin et al., 2007). Cells cultured in both cell culture media (HGm and OXPHOSm) were plated at different cell densities (2500, 5000, 10 000, 20 000, and $\left.40000 \mathrm{cells} / \mathrm{cm}^{2}\right)$ and several time points were used for the characterization of cell growth $(24,48,72,96,120$, and $144 \mathrm{~h})$. Regarding cell proliferation measurements, our results showed that cells grew exponentially when cultured in HGm or OXPHOSm and that BJ cells submitted to the OXPHOSm presented a proliferation profile similar to cells cultured in HGm, suggesting an effective adaptation to a more oxidative metabolism that supports the proliferation in OXPHOSm (Supplementary Figs. 1A and 1B). Regarding cell viability measurements, our results demonstrated that cells cultured in HGm increased their metabolic activity up to $96 \mathrm{~h}$, while their metabolic activity slightly decreased after $120 \mathrm{~h}$ (Supplementary Figure 1C). Cells cultured in OXPHOSm maintained their metabolic activity up to $144 \mathrm{~h}$ of culture time (Supplementary Figure 1D). These results allowed us to select the appropriate cell density to perform the assays and the maximum time point to be used during the experiments, to guarantee that cells were in exponential growth phase.

To assess mitochondrial network morphology and mitochondrial membrane potential $\left(\Delta \psi_{\mathrm{m}}\right)$ we used vital epifluorescence imaging of cells loaded with a nonquenching concentration of the $\Delta \psi_{\mathrm{m}}$-sensitive fluorescent dye TMRM. As shown in Figure 1A, cells cultured in OXPHOSm showed a more elongated mitochondrial network and a tendency for an increased TMRM relative fluorescence $(p=.0781)$ (Figure 1B)

Afterwards, we determined OCR normalized by cell mass in both groups of cells by using the Seahorse $\mathrm{XF}^{\mathrm{e}} 96$ Extracellular Flux Analyzer. As expected, our results showed that alteration of cell culture medium from HGm to OXPHOSm increased basal respiration (Figs. 1C and 1D), ATP production-associated OCR (Figs. 1C and $1 \mathrm{E}$ ), maximal respiration (Figs. $1 \mathrm{C}$ and $1 \mathrm{~F}$ ) and affected proton 
Table 1. Sequences of Primers Used for the Analysis of Mitochondrial DNA Copy Number and Gene Transcripts

\begin{tabular}{|c|c|c|c|}
\hline Gene & Accession Number & Forward Primer & Reverse Primer \\
\hline h_Mito3 & NC_012920 & CACTTTCCACACAGACATCA & TGGTTAGGCTGGTGTTAGGG \\
\hline$h \_$RNAse P & AF479321 & CCCCGTTCTCTGGGAACTC & TGTATGAGACCACTCTTTCCCATA \\
\hline ND1 & NC_012920 (3307-4262) & ACGCCATAAAACTCTTCACCAAAG & TAGTAGAAGAGCGATGGTGAGAGCTA \\
\hline ND2 & NC_012920 (4470-5511) & AACCAAACCCAGCTACGCAA & AGCTTGTTTCAGGTGCGAGA \\
\hline ND3 & NC_012920 (10059-10404) & TGCGGCTTCGACCCTATATC & GTAGGGCTCATGGTAGGGGTA \\
\hline ND4 & NC_012920 (10760-12137) & GCTCCATCTGCCTACGACAA & GCTTCAGGGGGTTTGGATGA \\
\hline ND4L & NC_012920 (10470-10766) & AАСАСССАСТСССТСТTAGC & AGTCTAGGCCATATGTGTTGGAG \\
\hline ND5 & NC_012920 (12337-14148) & AGTTACAATCGGCATCAACCAA & CCCGGAGCACATAAATAGTATGG \\
\hline ND6 & NC_012920 (14149-14673) & CACCCACAGCACCAATCCTA & ACAGCGATGGCTATTGAGGAG \\
\hline CYT B & NC_012920 (14747-15887) & ССАССССАТССААСАТСТСС & GCGTCTGGTGAGTAGTGCAT \\
\hline $\operatorname{COXI}$ & NC_012920 (5904-7445) & ATACCAAACGCСССТСTTCG & TGTTGAGGTTGCGGTCTGTT \\
\hline COX II & NC_012920 (7586-8269) & GTACTCCCGATTGAAGCCCC & TCGTGTAGCGGTGAAAGTGG \\
\hline COX III & NC_012920 (9207-9990) & CCAATGATGGCGCGATG & CTTTTTGGACAGGTGGTGTGTG \\
\hline ATP6 & NC_012920 (8527-9207) & GCGCCACCCTAGCAATATCA & GCTTGGATTAAGGCGACAGC \\
\hline ATP 8 & NC_012920 (8366-8572) & АСТАССАССТАССТСССТСАС & GGATTGTGGGGGCAATGAATG \\
\hline DDR2 & NM_001014796.1 & TCACCTTCCAATCAGATGCT & TCCGAGTGTTGCTGTCAT \\
\hline HSP47 & NM_001207014.1 & GTTCTTCAAGCCACACTG & TTCCTTCTCGTCGTCGTA \\
\hline PXN & NM_002859.3 & ATCCACCAGCAGCCTCAG & GAGAGCCAACACTGTCCTG \\
\hline VLC & NM_003373.3 & CTCGTCCGGGTTGGAAAAGAG & AGTAAGGGTCTGACTGAAGCAT \\
\hline ACTA2 & NM_001613 & TTACTACTGCTGAGCGTGAG & AGGCAACTCGTAACTCTTCTC \\
\hline ALDH1 & NM_000689.4 & АСTCСTCTCACTGCTCTC & САAСTTGCСАAССТСТGT \\
\hline GALK1 & NM_000154.1 & TTCAGTGCAGTGGTGGTCAG & CTATTGTGCCCGAGTCTGGA \\
\hline GALE & NM_000403.3 & GGGCACAGGCTATTCAGT & ACCTTGTACGGGATCTTCTTC \\
\hline 18S RNA & NR_003386 & ACTCAACACGGGAAACCTC & ACCAGACAAATCGCTCCAC \\
\hline
\end{tabular}

leak (Figs. 1C and 1H), while spare respiratory capacity (Figs. 1C and $1 \mathrm{G}$ ) and nonmitochondrial respiration (Figs. $1 \mathrm{C}$ and $1 \mathrm{I}$ ) were not altered. Moreover, because OCR was generally increased, we corroborated these results by determining the intracellular adenine nucleotides pool by HPLC. Figure 2 shows that ATP (Figure 2A), AMP (Figure 2C), and ATP/ADP (Figure 2D) were increased when cells were cultured in OXPHOSm, while ADP (Figure 2B) and energy charge were decreased (Figure 2E).

\section{Mitochondria-Related Transcripts and Proteins Were Increased during Mitochondrial Remodeling}

To evaluate the effects of mitochondrial remodeling at transcriptional and translational levels, we evaluated the effects of forcing oxidative capacity in mitochondria-related gene expression and proteins levels by RT-PCR and Western blotting, respectively. We demonstrated that gene expression of mitochondrial respiratory chain subunits was increased in cells cultured in OXPHOSm, namely NADH dehydrogenase subunit 1 (ND1) (Figure 3A), NADH dehydrogenase subunit 2 (ND2) (Figure 3B), NADH dehydrogenase subunit 3 (ND3) (Figure 3C), NADH dehydrogenase subunit 4 (ND4) (Figure 3D), NADH dehydrogenase subunit 4L (ND4L) (Figure 3E), NADH dehydrogenase subunit 5 (ND5) (Figure 3F), NADH dehydrogenase subunit 6 (ND6) (Figure 3G), cytochrome B (CYB) (Figure 3H), cytochrome c oxidase subunit 1 (COX1) (Figure 3I), cytochrome c oxidase subunit 2 (COX2) (Figure 3J), cytochrome c oxidase subunit 3 (COX3) (Figure $3 \mathrm{~K}$ ), and ATP synthase Fo subunit 8 (ATP8) (Figure 3M). ATP synthase Fo subunit 6A (ATP6A) gene expression was not altered (Figure $3 \mathrm{~L}$ ). We also evaluated the protein content of mitochondrial respiratory chain subunits, membrane carriers, and translocators, as well as mitochondrial biogenesis-related proteins. Regarding mitochondrial respiratory chain subunit proteins, our results showed that mitochondrial complex I-related subunit (NDUFB8) (Figs. 4A and 4B), mitochondrial complex IVrelated subunit (MTCO1) (Figs. 4A and 4E), and ATP synthase- related subunit (ATP5A) (Figs. 4A and 4F) were increased when cells were cultured in OXPHOSm (Figure 4). Mitochondrial complex II (SDHB) (Figs. 4A and 4C) and complex III-related subunits (UQCRC2) (Figs. 4A and 4D) were not altered. We also determined that ATP synthase subunit 5A (Figs. $4 \mathrm{G}$ and $4 \mathrm{H}$ ) and Ubquinol-cytochrome $c$ reductase core protein (Figs. 4G and 4I), outer mitochondrial membrane-related protein porin (VDAC1) (Figs. 4G and 4J), and mitochondrial matrix cyclophilin D (Figs. $4 \mathrm{G}$ and $4 \mathrm{~K}$ ) were increased when OXPHOSm was used to culture cells (Figure 4). Also, increased TOM20 content was observed when cells were cultured in OXPHOSm (Figure 5C). Mitochondrial biogenesis-indicator PGC1- $\alpha$ (Figure 5A), and Krebs cycle enzyme citrate synthase (Figure 5B) were not altered, the latter one showing a statistical trend for an increase when cells were cultured in OXPHOSm (Figure 4). Considering that mtDNA copy number can also be an indicator of overall mitochondrial mass, capacity, and fitness, we assessed mtDNA copy number by RT-PCR. We found out that cells cultured in OXPHOSm showed increased mtDNA copy number when comparing with cells cultured in HGm (Figure 5D).

\section{Cytotoxicity from Mitochondrial Poisons Is Higher When BJ Cells Undergo Mitochondrial Remodeling and Rely on Oxidative Phosphorylation for ATP Production}

To confirm whether forcing mitochondrial metabolism in human skin fibroblasts increased the susceptibility to mitochondrial poisons, we further evaluated the cytotoxicity of well-known mitochondrial poisons, namely mitochondrial complex I inhibitor (rotenone), Fo-ATP synthase inhibitor (oligomycin), and the mitochondrial uncoupler FCCP, in a dose- and time-dependent manner. As anticipated, our results showed that after 6 and $24 \mathrm{~h}$ of rotenone treatment, cell mass decreased approximately $50 \%$ when cells were cultured in OXPHOSm for all concentrations tested, showing even a more severe response after $48 \mathrm{~h}$ of treatment, reaching more than $90 \%$ of cell mass 
A

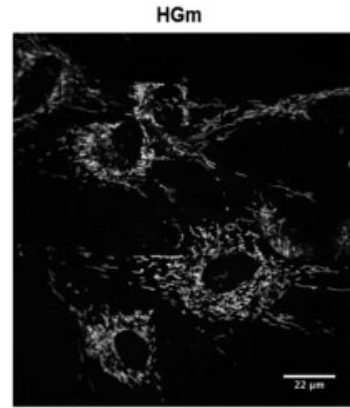

OXPHOSm

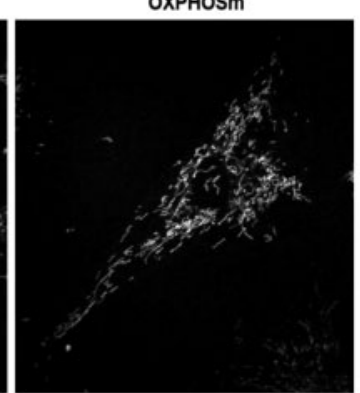

B

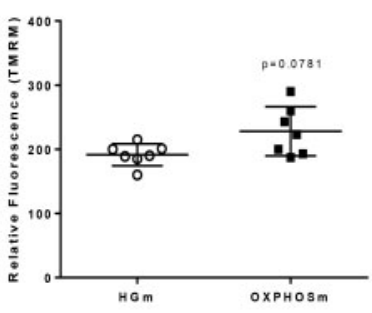

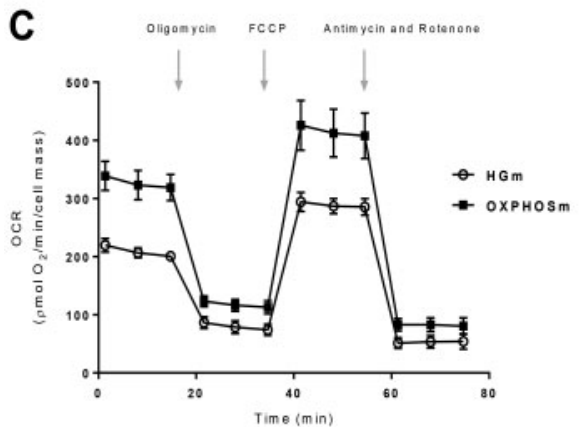

$\mathbf{F}$

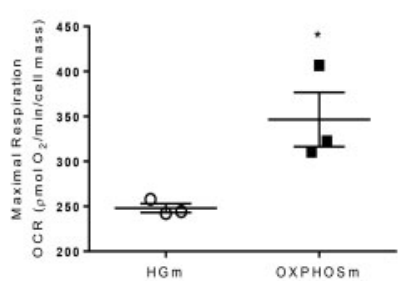

G

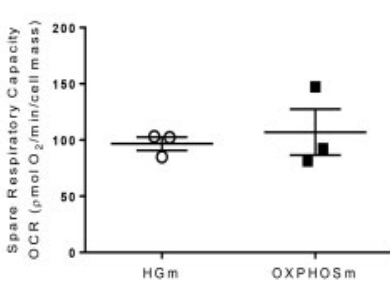

D

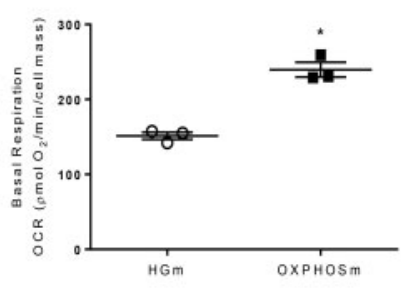

H

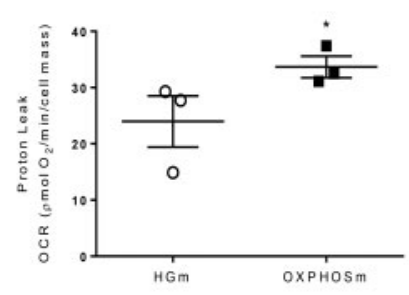

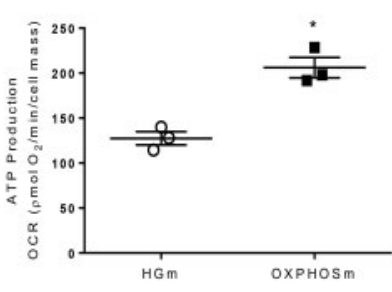

I

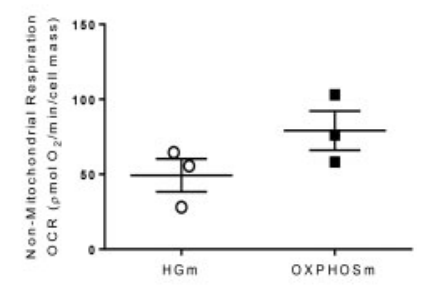

Figure 1. Metabolic remodeling of BJ human skin fibroblasts increased OCR. Cells were cultured in HGm or OXPHOSm, as described in Materials and Methods section. A and B, Thirty minutes prior the end of the treatment time, cells were incubated with $100 \mathrm{nM}$ TMRM in a buffer solution and analyzed using epifluorescence microscopy for characterization of the mitochondrial network of the BJ cells in both media. White scale bar corresponds to $22 \mu \mathrm{m}$. C-I, Seahorse XF 96 Extracellular Flux Analyzer was used to measure cellular OCR (C). Several respiratory parameters were evaluated: cell basal respiration (D, measurement prior to oligomycin addition minus nonmitochondria-derived OCR), OCR associated to ATP production (E, basal respiration minus proton leak), cell maximal respiration (F, maximal measurement after FCCP addition minus nonmitochondria-derived $\mathrm{OCR}$ ), spare respiratory capacity ( $\mathrm{G}$, maximal respiration minus basal respiration), proton leak ( $\mathrm{H}$, minimal measurement after oligomycin injection minus nonmitochondrial-derived OCR), and nonmitochondrial respiration (I, minimal measurement after rotenone and antimycin A addition). OCR were normalized by cell mass using the SRB method. Data shown are means \pm SEM of 4 independent experiments. ${ }^{*} p<.05$ denotes a significant difference between groups.

loss (Figure 6A). For cells cultured in HGm, cytotoxic effects of rotenone were only observed after $48 \mathrm{~h}$, for all rotenone concentrations used. Cells cultured in OXPHOSm were also more susceptible to oligomycin treatment. At the $6 \mathrm{~h}$ time point, $10 \mu \mathrm{M}$ oligomycin decreased cell mass, while at 24 and $48 \mathrm{~h}, 4$ and $10 \mu \mathrm{M}$ oligomycin caused a significant decrease in BJ cell mass (Figure 6B). We also verified that 1, 2, and $4 \mu \mathrm{M}$ FCCP decreased cell mass after $6 \mathrm{~h}$ of treatment in cells cultured in OXPHOSm. The same results were observed for all FCCP concentrations tested at 24 and $48 \mathrm{~h}$ (Figure 6C). No significant alterations were observed in BJ cell mass for the tested concentrations of oligomycin and FCCP when cells were cultured in HGm (Figs. 6B and 6C).

\section{Paxillin Gene Expression Was Increased in Human Skin Fibroblasts When Mitochondrial Capacity Was Forced}

Fibroblasts are found in every tissue of the body and are considered as differentiated cells, which are responsible for the synthesis and remodeling of extracellular matrix in tissues (Alt et al., 2011). Depending on their location, fibroblasts display multiple morphologies (Baum and Duffy, 2011). In order to evaluate whether artificial up-regulation of mitochondrial function alters BJ fibroblast differentiation status, we measured gene expression of some differentiation markers, including fibroblast markers, myofibroblast markers, and mesenchymal cell markers, while also evaluating transcripts related with galactose utilization metabolism. This experimental aim is important because the differentiation state of the cells can determine the metabolic phenotype and vice-versa (Vega-Naredo et al., 2014). Figure 7 shows that myofibroblast marker paxillin gene expression $(\mathrm{PXN})$ was increased when cells were cultured in OXPHOSm (Figure 7C), while no alterations were found in fibroblast markers discoidin domain receptor tyrosine kinase 2 (DDR2) and heat shock protein 47 (HSP47), in myofibroblast markers vinculin (VCL) and actin (ACTA2), as well as in mesenchymal marker aldehyde dehydrogenase 1 family member 1 (ALDH1) gene expression. Regarding galactose utilizationrelated enzymes, we observed that UDP-galactose-4-epimerase (GALE) gene expression was increased when cells were cultured in OXPHOSm (Figure 7H), while no alteration was found in galactokinase 1 (GALK1) gene expression (Figure 7). 
A

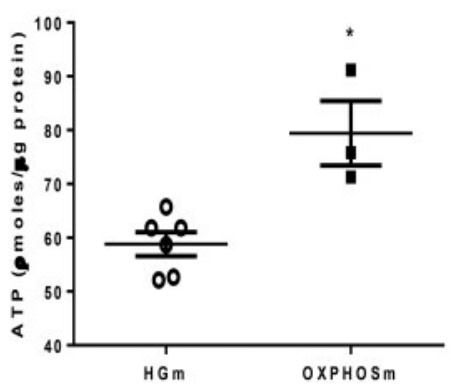

D

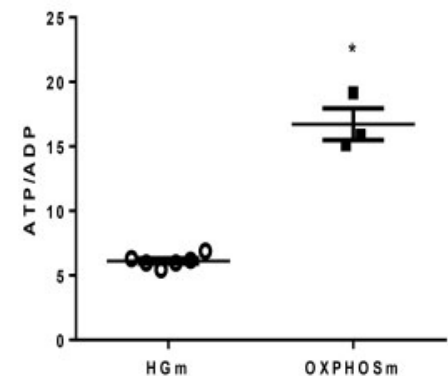

B

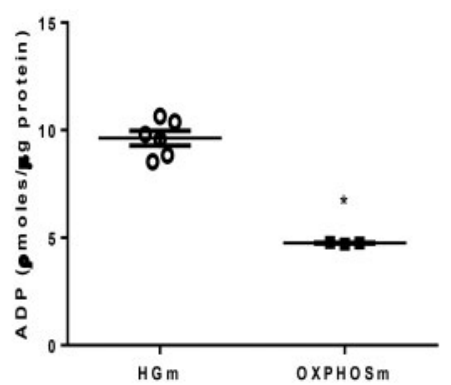

E

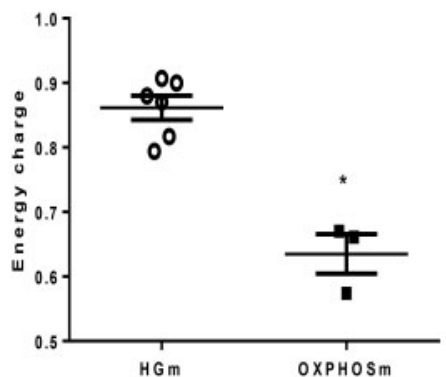

C

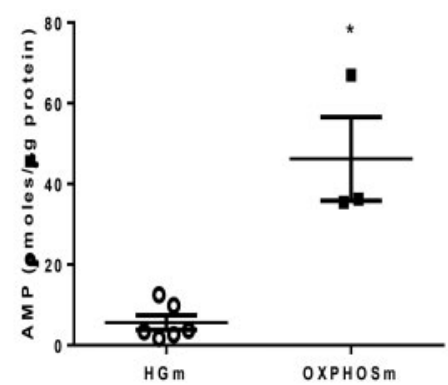

OXPHOSm

Figure 2. Metabolic remodeling of BJ fibroblasts lead to alterations in adenosine nucleotides levels. Cells were cultured in HGm or OXPHOSm, as described in Materials and Methods section. Adenosine nucleotides, namely ATP (A), ADP (B), and AMP (C) were evaluated by HPLC. [ATP]/[ADP] ratio (D) and energy charge (E; [ATP] + 0.5 $[\mathrm{ADP}]) /([\mathrm{ATP}]+[\mathrm{ADP}]+[\mathrm{AMP}])$ were also calculated. Data shown are means \pm SEM of $4-5$ independent experiments. ${ }^{*} p<.05$ denotes a significant difference between groups.

\section{DISCUSSION}

Primary cells can have several advantages to assess mitochondria-induced toxicity, including relevant metabolism and human accessibility and clinical translation (Auburger et al., 2012; Marroquin et al., 2007). Fibroblasts are adherent mesenchymal cells that play important roles during tissue development, maintenance, and repair, reflecting cumulative cell damage and mutations. Due to its localization human skin fibroblasts may be isolated from patients by a less-invasive method (Auburger et al., 2012). Taking advantage of these characteristics, human skin fibroblasts have been used to study several diseases, namely Leigh syndrome (Cameron et al., 2004) and neurodegenerative disorders such as Parkinson's and Alzheimer's disease (Ambrosi et al., 2014; Hu et al., 2015).

Several approaches have been tested to uncover drug-induced mitochondrial toxicity, namely by the use of a glucose-free/galactose/glutamine/pyruvate-containing medium (Marroquin et al., 2007). However, a full picture of fibroblast mitochondrial remodeling when using the modified culture media is still lacking. Moreover, it was not clear whether fibroblast differentiation status would change by forcing mitochondrial metabolism during culture, despite the fact that authors reported the importance of mitochondrial metabolic activity for cell differentiation state or proliferation rate (Mandal et al., 2011; VegaNaredo et al., 2014). Here, we performed a metabolic and phenotypic characterization of human skin fibroblasts after culturing them in a culture medium described to stimulate OXPHOS, showing increased mitochondrial capacity, alterations at the transcriptional and translational level, and increased expression of one focal adhesion-associated adaptor gene.

Using this strategy, it has previously been shown in HeLa human cervical cancer cells cultured in OXPHOSm that the mitochondrial matrix structure is condensed and with more developed cristae (Rossignol et al., 2004), which might have been due to a more efficient OXPHOS. This observation supports our results, as we measured that cells cultured in OXPHOSm had a more elongated mitochondrial network (Figure 1A), although without statistical significance regarding TMRM relative fluorescence $(p=.0781)$ (Figure 1A). These mitochondrial network morphological alterations were already associated with modifications on the metabolic status of the cell, including the increase in ATP synthase activity (Gomes et al., 2011). In fact, it was previously shown in HepG2, a human liver cancer cell line, that cellular growth rate was not altered regardless of the culture medium used, while oxygen consumption and ATP levels were increased when cells were cultured in OXPHOSm (Marroquin et al., 2007), which is in agreement with our results (Figs. 1 and 2, and Supplementary Figure 1). The increase in basal and maximal respiration in human skin fibroblasts cultured in OXPHOSm was not associated with increased spare respiratory capacity, suggesting that human skin fibroblasts might have the same response capacity during an energetic demand, regardless of the cell culture medium used (Figs. 1C-I). Concomitant with the increased oxygen consumption, we also found increased ATP and AMP levels (Figs. 2A and 2B) when OXPHOSm was used, while ADP levels were decreased 
A

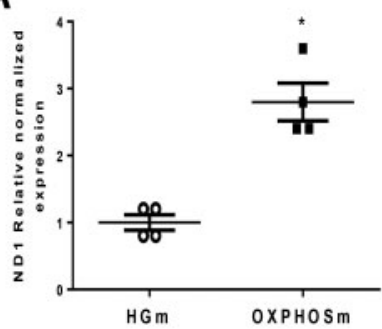

E

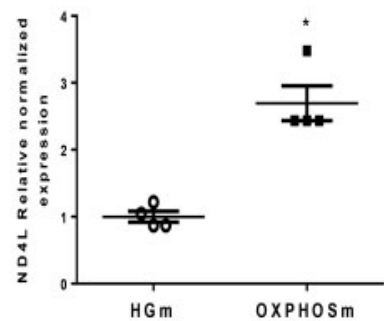

I

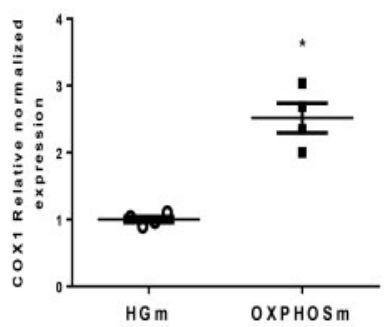

M

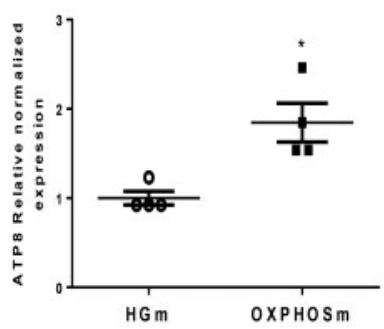

B

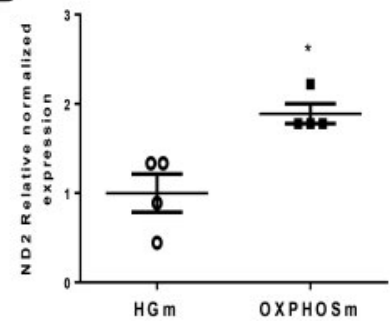

$\mathbf{F}$

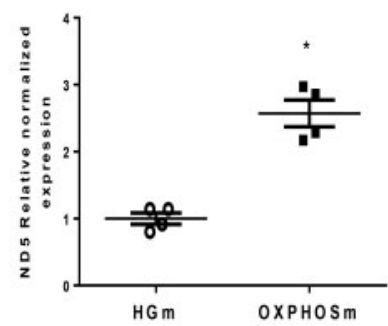

$J$

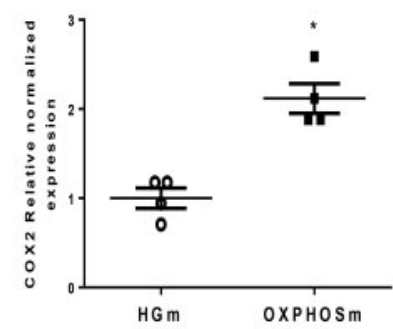

C

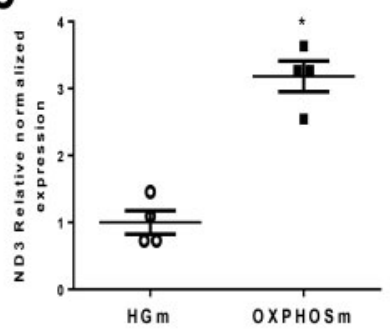

D

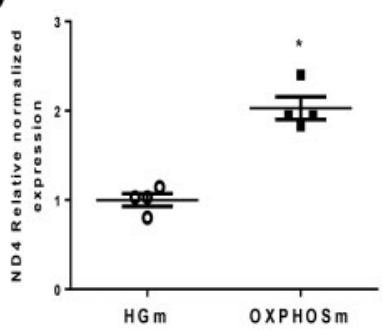

G

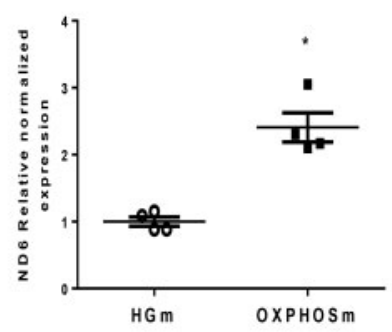

H

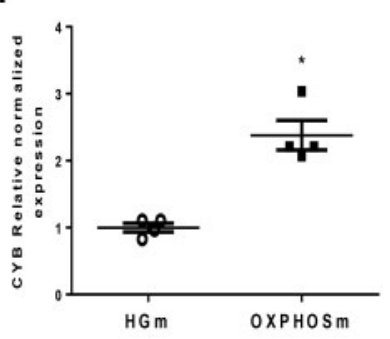

K

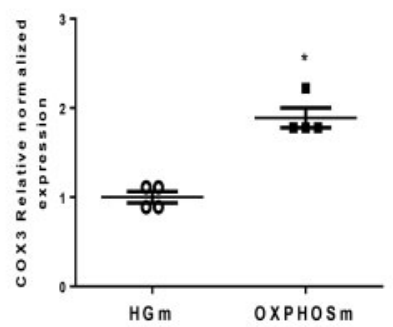

Figure 3. Increased mitochondrial oxidative capacity of BJ fibroblasts increased gene expression of mtDNA-encoded mitochondrial respiratory chain subunits. Cells were cultured in HGm or OXPHOSm, as described in Materials and Methods section. Total RNA was extracted, converted into cDNA, and amplified by real-time RT-PCR. Gene expression was normalized to $18 \mathrm{~S}$ RNA levels and divided by the value obtained for the controls cultured in HGm. Data shown are means \pm SEM of 4 independent experiments. ${ }^{*} p<.05$ denotes a significant difference between groups.

(Figure 2C). These results can mirror an increased respiration rate of the cells grown in OXPHOSm to maintain ATP levels (Warburg et al., 1967) because galactose oxidation through glycolysis does not result in a yield net ATP production, or results in a very slow ATP production, for survival and proliferation, cells were forced to rely on OXPHOS for ATP production (Rossignol et al., 2004). Taking in consideration that ATP synthase produces ATP from ADP and inorganic phosphate (Senior et al., 2002), this could explain the decreased ADP levels. The energy status of the cells controls many metabolic reactions (Gomes et al., 2011), we found out that cells grown in OXPHOSm exhibited a decrease energy charge, in fact, Atkinson and
Walton (1967) showed that ATP-generating pathways are stimulated by low energy charge. Consistently, we verified that human skin fibroblasts cultured in OXPHOSm presented increased ATP levels associated with a lower energy charge when comparing with their HGm counterparts (Figure 2E). Metabolic alterations, including increased OCR, promoted by the modified cell culture medium may have resulted from a stimulation of mitochondrial biogenesis, increase in protein amount or gene expression of subunits of mitochondrial respiratory chain, and increased flux of glutamine oxidation through TCA (Rossignol et al., 2004). It was demonstrated in HeLa and MRC-5 human fetal lung cell line, that forcing oxidative capacity increased total 
A $\quad$ B

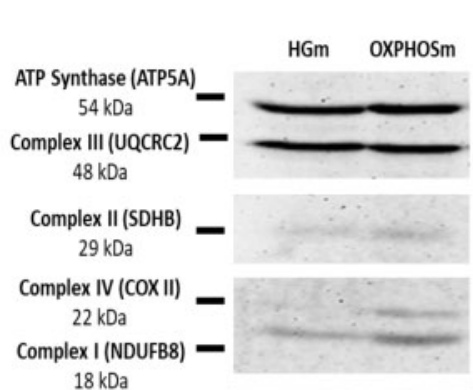

$18 \mathrm{kDa}$

Ponceau

Labeling

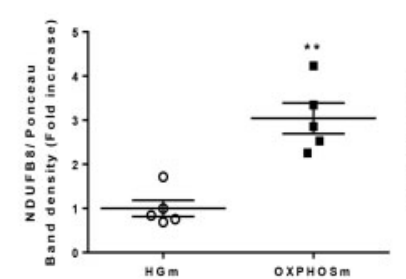

C

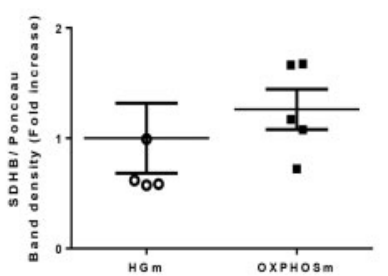

E

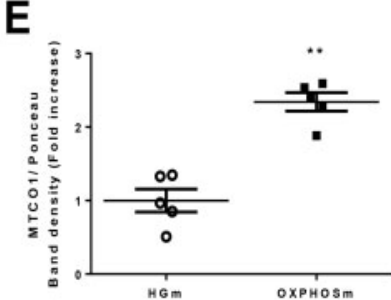

$\mathbf{F}$

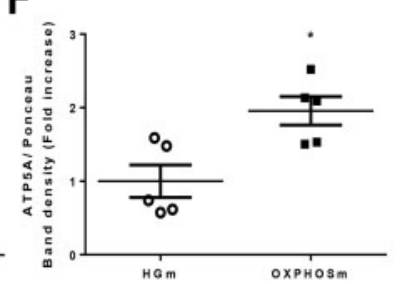

D

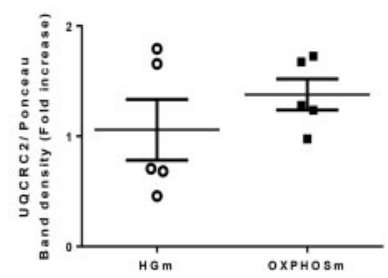

Figure 4. Metabolic remodeling of BJ fibroblasts increased protein levels of mitochondrial OXPHOS subunits and membrane proteins levels. Cells were cultured in HGm or OXPHOSm, as described in Materials and Methods section. Western blotting was used to detect: A-F, NDUFB8 (complex I subunit), UQCRC2 (complex III subunit), COX II (complex IV subunit), SDHB (complex II subunit), ATP5A (ATPase subunit Fo) and G to K, cyclophilin D (mitochondrial matrix chaperone), VDAC1 (mitochondrial outer membrane porin), complex Va (ATP5A), and complex III core 1 (mitochondrial inner membrane) in total fractions from BJ cell line. Ponceau was used as loading control (Romero-Calvo et al., 2010). Data shown are means \pm SEM of 4 independent experiments. ${ }^{*} p<.05$ and ${ }^{* *} p<.01$ denote a significant difference between groups.

amount of mitochondrial subunits-related proteins and mitochondrial enzymatic activities (Rossignol et al., 2004). We have also previously demonstrated in $\mathrm{H} 9 \mathrm{c} 2$ cardiomyoblasts that OXPHOSm increased mtDNA copy number, OCR associated with ATP production and the protein abundance of some OXPHOS subunits (Deus et al., 2015). In these human primary human cells, we measured not only the effects of mitochondrial remodeling at translational as well as transcriptional level, observing an increased in mtDNA copy number, and up-regulation of mitochondrial subunits-related gene expression and an increase in the mitochondrial proteins content related with OXPHOS (Figs. 3-5), suggesting that a mitochondrial transcriptional reprogramming occurs and leads to structural and functional mitochondrial alterations in human skin fibroblasts, as example, the increase in the VDAC, the main channel for respiratory substrates to cross the mitochondrial outer membrane. Protein content of TOM20, an indicator of mitochondrial mass (Burbulla et al., 2014), was increased and in agreement with other mitochondrial mass indirect indicators (mtDNA, mitochondrial
OXPHOS subunits, and citrate synthase) confirming an increase in mitochondrial mass and subsequently mitochondrial biogenesis. Nevertheless, no differences were found in protein content of PGC1- $\alpha$, a master regulator of mitochondrial biogenesis (Figure 5) (Onishi et al., 2014), advising that mitochondrial biogenesis induced by OXPHOSm is triggered by a PGC1- $\alpha$-independent mechanism. Similarly, it was previously demonstrated in mouse muscle myoblasts C2C12, that mitochondrial biogenesis can be induced by supra-physiological levels of sodium pyruvate through a PGC1- $\alpha$-independent mechanism (Wilson et al., 2007). No alterations in protein content of selected mitochondrial complex II and III subunits, both encoded by nuclear genome (Fernandez-Vizarra and Zeviani, 2015) were observed between the two cellular culture media (Figs. 4C and 4D). This observation suggests that increased reserves these two complexes, or at least these subunits, are needed even when glycolytic pathway is used, possibly related to other biosynthetic processes (Rossignol et al., 2004). 
A
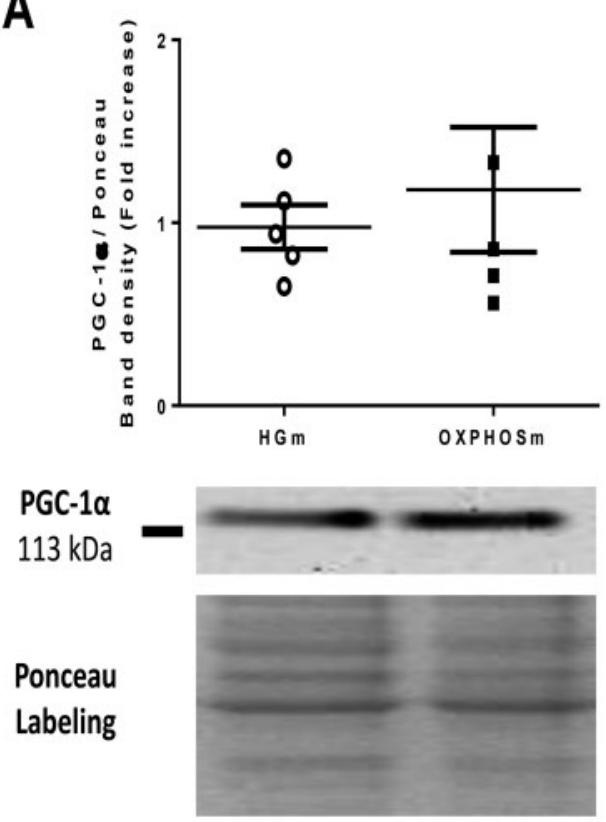

C

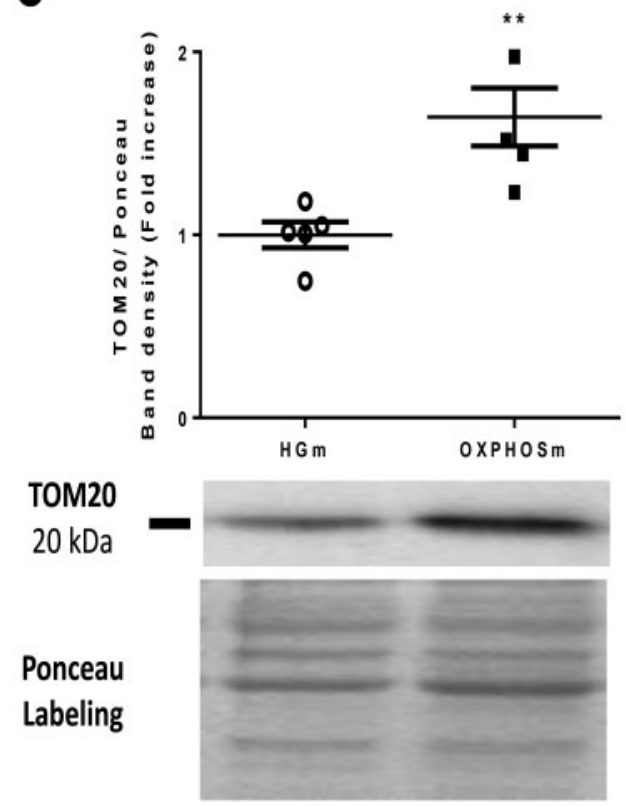

B
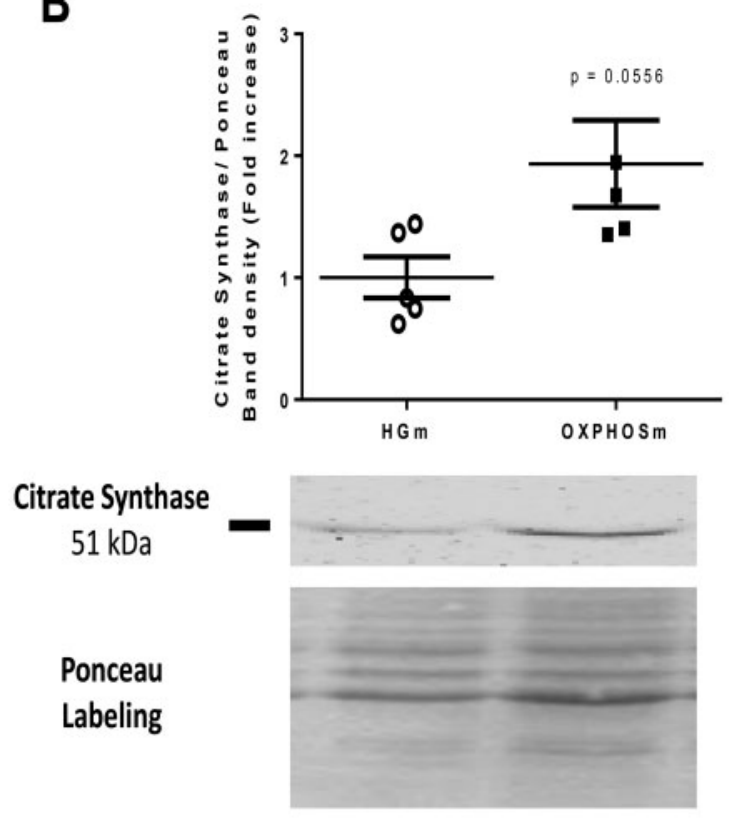

D

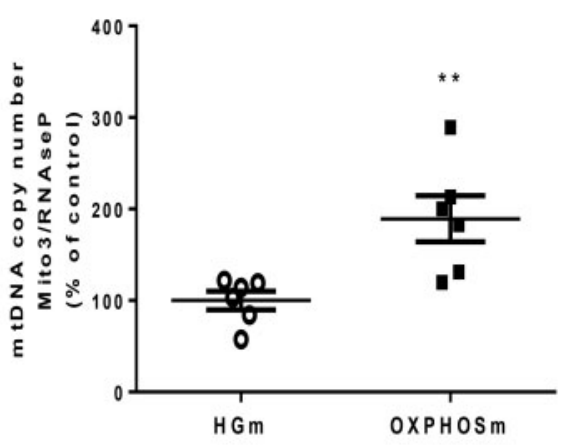

came more susceptible to mitochondrial poisons when OXPHOS is being mainly used for ATP production (Figure 6). Similarly, it has already been demonstrated that HepG2 cells were more susceptible to mitochondrial electron transport chain inhibitors, such as rotenone, antimycin and oligomycin when cells were cultured in OXPHOSm (Marroquin et al., 2007), which caused also an increase in OCR, and increased susceptibility to mitochondrial inhibitors (Marroquin et al., 2007).
Considering that fibroblasts are a morphologically heterogeneous population of cells with diverse morphology depending on their location and activity (Chang et al., 2014), we further evaluated whether mitochondrial remodeling promoted fibroblast differentiation, namely directed toward myofibroblast or mesenchymal stem cell-like (Baum and Duffy, 2011; Valenti et al., 2001). Several reports have showed that lung fibroblasts were heterogeneous in cell surface markers expression and levels of collagen production (Fries et al., 1994; Habiel and 
A

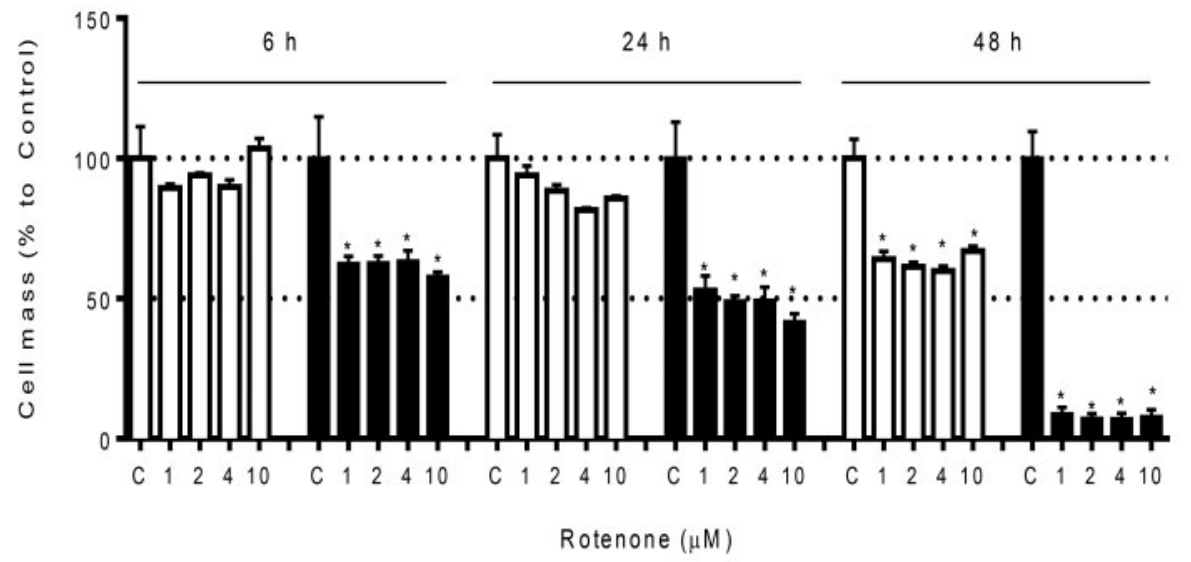

B

$6 \mathrm{~h}$

$24 \mathrm{~h}$

$48 \mathrm{~h}$

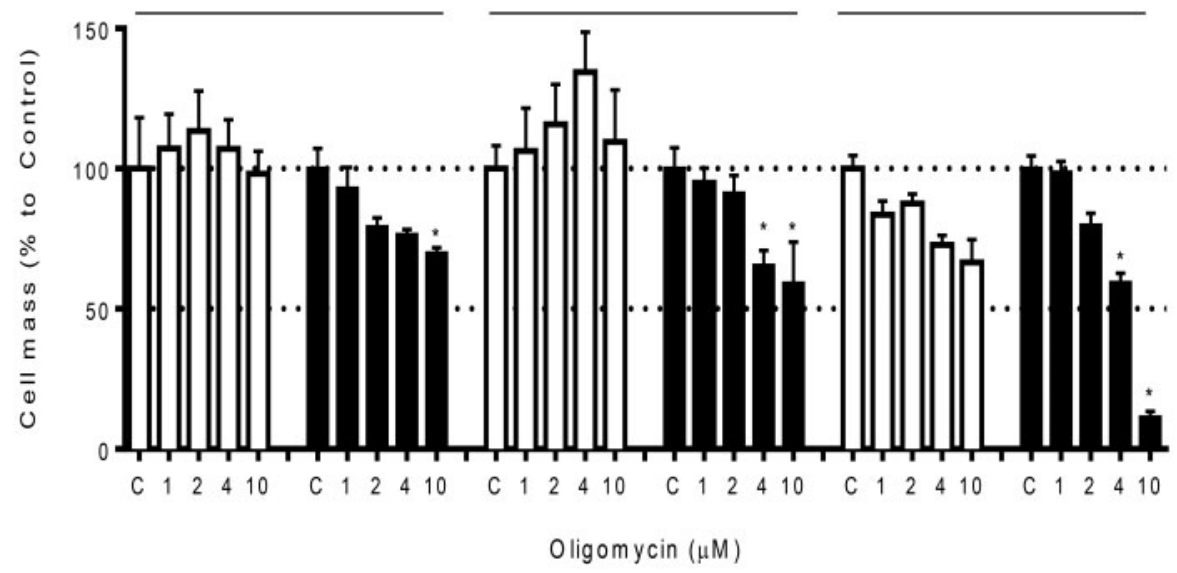

C

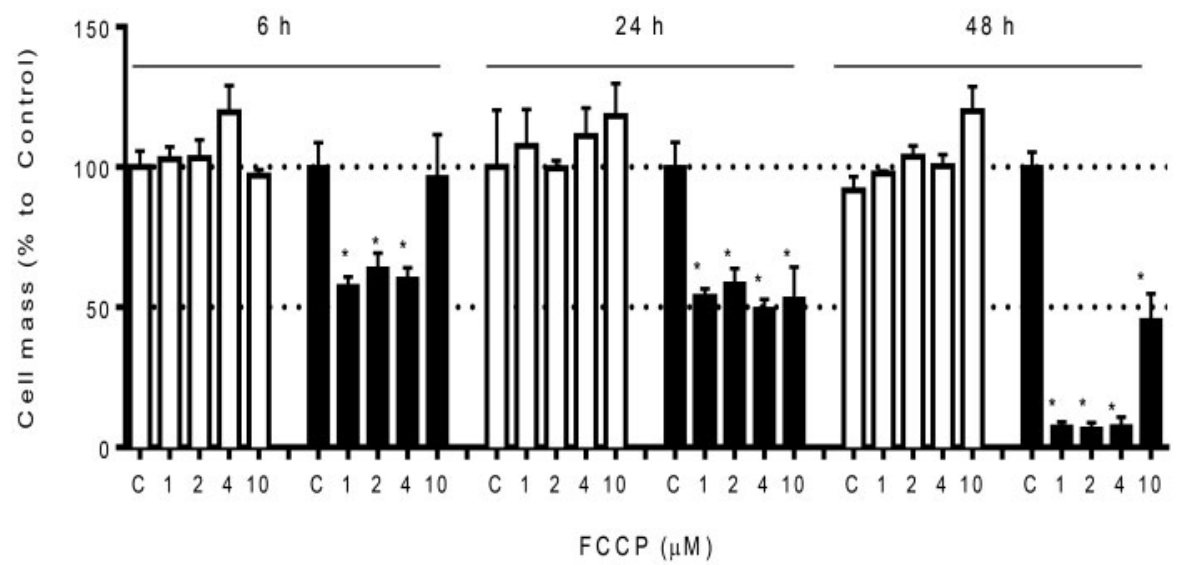

Figure 6. BJ human skin fibroblasts cultured in OXPHOSm (black bars) were more susceptible to mitochondrial poisons compared with cells cultured in HGm (white bars). Cells cultured in HGm or OXPHOSm were incubated with mitochondrial poisons, namely rotenone (mitochondrial complex I inhibitor) (A), FCCP (B), and Oligomycin (ATP synthase inhibitor) (C) for 6, 24, and $48 \mathrm{~h}$ at different concentrations, as described in Materials and Methods section. Data shown are means \pm SEM of 4 independent experiments. ${ }^{*} p<.05$ denotes a significant difference from the respective control.

Hogaboam, 2017). Furthermore, periodontal fibroblasts were also described as a heterogeneous population based on morphology, glycogen pools, and collagen production (Alt et al., 2011). We analyzed standard molecular markers of fibroblasts, myoblasts, and mesenchymal stem cell-like, as well as transcripts which coded proteins involved in galactose utilization. Galactose in OXPHOSm must be phosphorylated by galactokinase 1, resulting in galactose-1-phosphate. Galactose-1- 
A

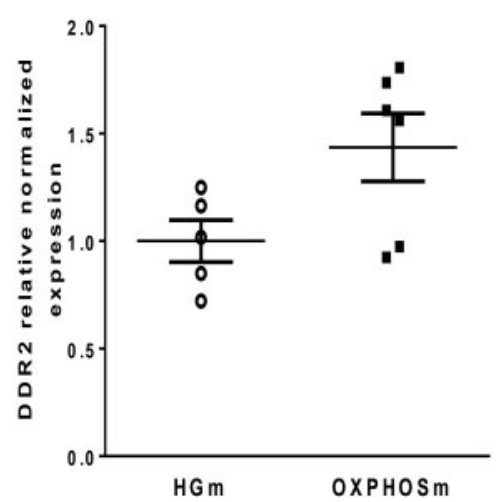

D

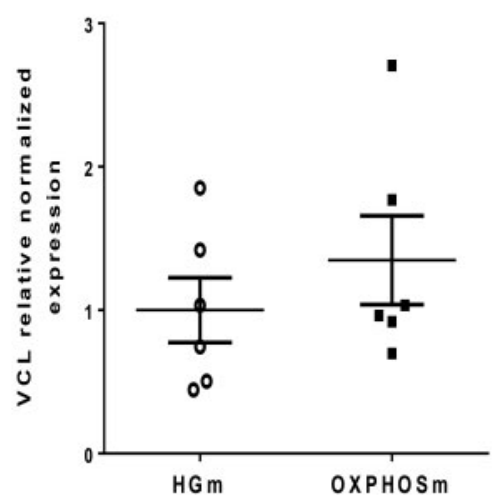

G

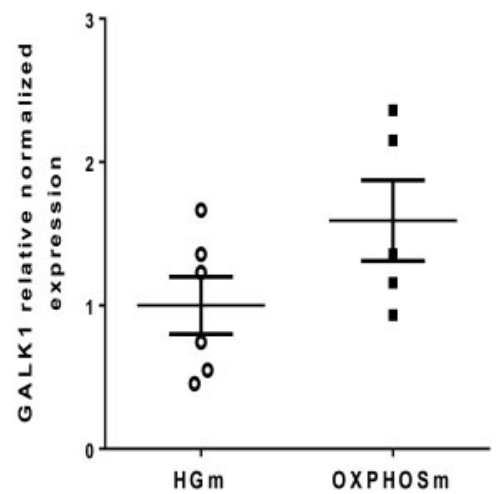

B

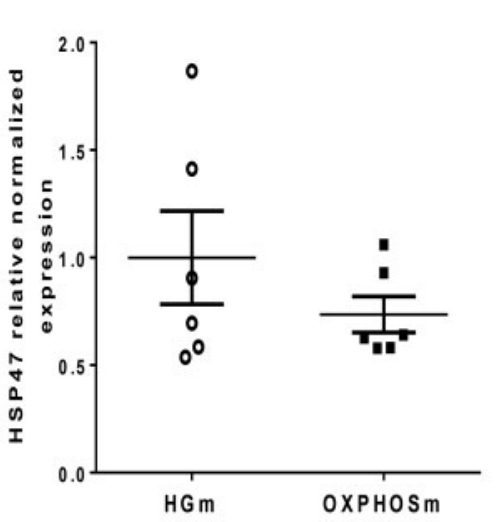

E

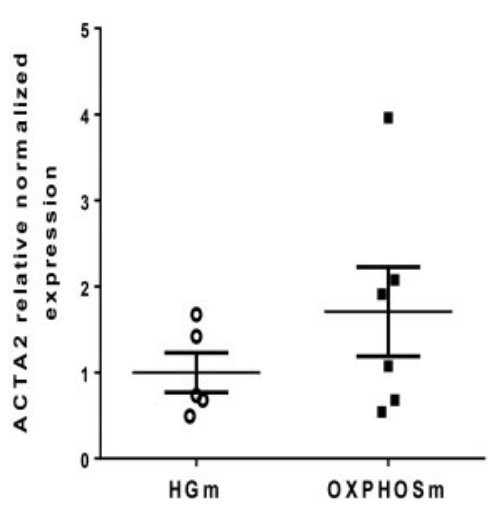

$\mathbf{F}$

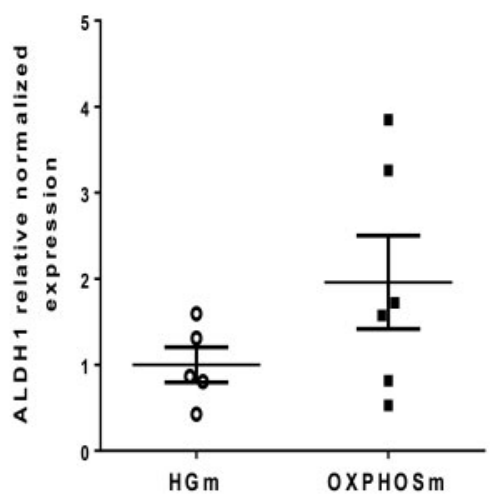

phosphate is then converted into glucose-1-phosphate by uridyl transferase, which uses UDP-glucose (Cuthbert et al., 2008). UDP-galactose-4-epimerase catalyzes the reversible conversion of UDP-galactose to UDP-glucose in galactose utilization metabolism (Cuthbert et al., 2008). With this work, we demonstrated that the mitochondrial remodeling promoted by OXPHOSm in human skin fibroblasts increased UDP-galactose-4-epimerase (GALE) gene expression (Figure 7G), possibly as an adaptive response due to the modified cell culture medium used. We also demonstrated that the mitochondrial remodeling promoted by
OXPHOSm in human skin fibroblasts did not affect the differentiation markers evaluated (Figure 7), with exception of paxillin gene expression, which was increased when OXPHOSm was used (Figs. 7C and 7G). Paxillin gene encodes a focal adhesion protein involved in actin-membrane attachment at sites of cell adhesion to the extracellular matrix. These dynamic interactions are essential for cellular adhesion, migration, and survival (Mackinnon et al., 2011). Moreover, it was also described that mutations in paxillin gene lead to mitochondrial dynamics and mitochondrial physiology dysregulation in human embryonic 
kidney epithelial cells, HEK-293 (Kawada et al., 2013). For the same cell line, it was also shown that paxillin mutations induced cell survival advantage and co-localized with the antiapoptotic protein Bcl-2 (Kawada et al., 2013). We can postulate that the increased expression of paxillin was induced by forcing oxidative capacity (Figure 7) and represents an adaptive response to accompanied alterations in mitochondrial physiology and dynamics to promote mitochondrial function and support human skin fibroblasts survival.

In conclusion, we show here that by using a modified culture media frequently used in research, mitochondrial capacity was increased in human skin fibroblasts accompanied by relevant mitochondrial transcriptional and translational alterations. Furthermore, increased focal adhesion-associated adaptor gene expression was also measured. Hereby, we provide the first comprehensive analysis of the changes that occur in mitochondrial function and structure in a human primary skin fibroblast cell line when cultured in OXPHOSm. Because fibroblasts can be collected from patients by noninvasive methods and allow the characterization of disease pathophysiology, our work highlights the possibility of using individual human primary fibroblast and applies the cell culture media switch strategy for taking into consideration the mitochondrial heteroplasmy when measuring drug-induced mitochondrial liabilities or drug treatment for personalized medicine, similarly to what was previously described by us in a panel of mouse embryonic fibroblasts (Pereira et al., 2012). Measuring the individual mitochondrial response to chemical agents in skin fibroblasts can lead to significant savings in deterioration of patient health and shortening the time and cost for drug development.

\section{SUPPLEMENTARY DATA}

Supplementary data are available at Toxicological Sciences online.

\section{FUNDING}

This work was supported by FEDER funds through the Operational Programme Competitiveness FactorsCOMPETE2020 and national funds by FCT-Foundation for Science and Technology under research grants PTDC/DTPFTO/2433/2014, POCI-01-0145-FEDER-016659, and strategic project COMPETE: POCI-01-0145-FEDER-007440. Also supported by QREN project 4832 with reference CENTRO-07ST24-FEDER-002008 financed through FEDER. C.M.D. (SFRH/ BD/100341/2014) was supported by FCT PhD-fellowships and S.P.P. (SFRH/BPD/116061/2016) and T.C.O. (SFRH/BPD/101169/ 2014) were supported by FCT Post-Doctoral fellowships. The work was also funded by Montepio Foundation under the project "An Epigenetic Engineering Approach to Reverse the Parkinson Disease Cell State (PD-state)” (CPD0028001; 2015).

\section{CONTRIBUTIONS}

S.P.P., C.M.D., T.L.S., and T.C.O. performed experiments, analyzed results, generated figures, and wrote the manuscript. P.J.O. and S.P.P. conceived and supervised the study, designed experiments, and wrote part of the manuscript. All authors revised and agreed in the final form of the manuscript.

\section{CONFLICT OF INTEREST}

None of the authors has any conflict of interest. The funding agencies had no role in the decision to publish the manuscript.

\section{REFERENCES}

Alt, E., Yan, Y., Gehmert, S., Song, Y. H., Altman, A., Gehmert, S., Vykoukal, D., and Bai, X. (2011). Fibroblasts share mesenchymal phenotypes with stem cells, but lack their differentiation and colony-forming potential. Biol. Cell 103, 197-208.

Ambrosi, G., Ghezzi, C., Sepe, S., Milanese, C., Payan-Gomez, C., Bombardieri, C. R., Armentero, M.-T., Zangaglia, R., Pacchetti, C., Mastroberardino, P. G., et al. (2014). Bioenergetic and proteolytic defects in fibroblasts from patients with sporadic Parkinson's disease. Biochim. Biophys. Acta 1842, 1385-1394.

Arduino, D. M., Wettmarshausen, J., Vais, H., Navas-Navarro, P., Cheng, Y., Leimpek, A., Ma, Z., Delrio-Lorenzo, A., Giordano, A., Garcia-Perez, C., et al. (2017). Systematic identification of MCU modulators by orthogonal interspecies chemical screening. Mol. Cell 67, 711-723 e7.

Atkinson, D. E., and Walton, G. M. (1967). Adenosine triphosphate conservation in metabolic regulation. Rat liver citrate cleavage enzyme. J. Biol. Chem. 242, 3239-3241.

Auburger, G., Klinkenberg, M., Drost, J., Marcus, K., MoralesGordo, B., Kunz, W. S., Brandt, U., Broccoli, V., Reichmann, H., Gispert, S., et al. (2012). Primary skin fibroblasts as a model of Parkinson's disease. Mol. Neurobiol. 46, 20-27.

Baum, J., and Duffy, H. S. (2011). Fibroblasts and myofibroblasts: What are we talking about? J. Cardiovasc. Pharmacol. 57, 376-379.

Bradford, M. M. (1976). A rapid and sensitive method for the quantitation of microgram quantities of protein utilizing the principle of protein-dye binding. Anal. Biochem. 72, 248-254.

Burbulla, L. F., Fitzgerald, J. C., Stegen, K., Westermeier, J., Thost, A. K., Kato, H., Mokranjac, D., Sauerwald, J., Martins, L. M., Woitalla, D., et al. (2014). Mitochondrial proteolytic stress induced by loss of mortalin function is rescued by Parkin and PINK1. Cell Death Dis. 5, e1180.

Cameron, J. M., Levandovskiy, V., MacKay, N., and Robinson, B. H. (2004). Respiratory chain analysis of skin fibroblasts in mitochondrial disease. Mitochondrion 4, 387-394.

Carvalho, F. S., Burgeiro, A., Garcia, R., Moreno, A. J., Carvalho, R. A., and Oliveira, P. J. (2014). Doxorubicin-induced cardiotoxicity: From bioenergetic failure and cell death to cardiomyopathy. Med. Res. Rev. 34, 106-135.

Chang, Y., Li, H., and Guo, Z. (2014). Mesenchymal stem cell-like properties in fibroblasts. Cell. Physiol. Biochem. 34, 703-714.

Cuthbert, C., Klapper, H., and Elsas, L. (2008). Diagnosis of inherited disorders of galactose metabolism. Curr. Protoc. Hum. Genet. Chapter 17, Unit 17.5.

Deus, C. M., Zehowski, C., Nordgren, K., Wallace, K. B., Skildum, A., and Oliveira, P. J. (2015). Stimulating basal mitochondrial respiration decreases doxorubicin apoptotic signaling in H9c2 cardiomyoblasts. Toxicology 334, 1-11.

Fernandez-Vizarra, E., and Zeviani, M. (2015). Nuclear gene mutations as the cause of mitochondrial complex III deficiency. Front. Genet. 6, 134.

Fries, K. M., Blieden, T., Looney, R. J., Sempowski, G. D., Silvera, M. R., Willis, R. A., and Phipps, R. P. (1994). Evidence of fibroblast heterogeneity and the role of fibroblast subpopulations in fibrosis. Clin. Immunol. Immunopathol. 72, 283-292.

Gomes, L. C., Di Benedetto, G., and Scorrano, L. (2011). During autophagy mitochondria elongate, are spared from degradation and sustain cell viability. Nat. Cell Biol. 13, 589-598. 
Habiel, D. M., and Hogaboam, C. M. (2017). Heterogeneity of fibroblasts and myofibroblasts in pulmonary fibrosis. Curr. Pathobiol. Rep. 5, 101-110.

Hu, W., Qiu, B., Guan, W., Wang, Q., Wang, M., Li, W., Gao, L., Shen, L., Huang, Y., Xie, G., et al. (2015). Direct conversion of normal and Alzheimer's disease human fibroblasts into neuronal cells by small molecules. Cell Stem Cell 17, 204-212.

Kawada, I., Hasina, R., Lennon, F. E., Bindokas, V. P., Usatyuk, P., Tan, Y. H., Krishnaswamy, S., Arif, Q., Carey, G., Hseu, R. D., et al. (2013). Paxillin mutations affect focal adhesions and lead to altered mitochondrial dynamics: relevance to lung cancer. Cancer Biol. Ther. 14, 679-691.

Mackinnon, A. C., Tretiakova, M., Henderson, L., Mehta, R. G., Yan, B. C., Joseph, L., Krausz, T., Husain, A. N., Reid, M. E., and Salgia, R. (2011). Paxillin expression and amplification in early lung lesions of high-risk patients, lung adenocarcinoma and metastatic disease. J. Clin. Pathol. 64, 16-24.

Mandal, S., Lindgren, A. G., Srivastava, A. S., Clark, A. T., and Banerjee, U. (2011). Mitochondrial function controls proliferation and early differentiation potential of embryonic stem cells. Stem Cells 29, 486-495.

Marroquin, L. D., Hynes, J., Dykens, J. A., Jamieson, J. D., and Will, Y. (2007). Circumventing the Crabtree effect: replacing media glucose with galactose increases susceptibility of HepG2 cells to mitochondrial toxicants. Toxicol. Sci. 97, 539-547.

Masubuchi, Y., Kano, S., and Horie, T. (2006). Mitochondrial permeability transition as a potential determinant of hepatotoxicity of antidiabetic thiazolidinediones. Toxicology 222, 233-239.

Ong, M. M., Latchoumycandane, C., and Boelsterli, U. A. (2007). Troglitazone-induced hepatic necrosis in an animal model of silent genetic mitochondrial abnormalities. Toxicol. Sci. 97, 205-213.

Onishi, Y., Ueha, T., Kawamoto, T., Hara, H., Toda, M., Harada, R., Minoda, M., Kurosaka, M., and Akisue, T. (2014). Regulation of mitochondrial proliferation by PGC-1alpha induces cellular apoptosis in musculoskeletal malignancies. Sci. Rep. 4, 3916.

Pereira, C. V., Oliveira, P. J., Will, Y., and Nadanaciva, S. (2012). Mitochondrial bioenergetics and drug-induced toxicity in a panel of mouse embryonic fibroblasts with mitochondrial DNA single nucleotide polymorphisms. Toxicol. Appl. Pharmacol. 264, 167-181.

Pereira, G. C., Pereira, S. P., Tavares, L. C., Carvalho, F. S., Magalhaes-Novais, S., Barbosa, I. A., Santos, M. S., Bjork, J., Moreno, A. J., Wallace, K. B., et al. (2016). Cardiac cytochrome $\mathrm{c}$ and cardiolipin depletion during anthracycline-induced chronic depression of mitochondrial function. Mitochondrion 30, 95-104

Pereira, S. P., Pereira, G. C., Moreno, A. J., and Oliveira, P. J. (2009). Can drug safety be predicted and animal experiments reduced by using isolated mitochondrial fractions? Alternat. Lab. Anim. 37, 355-365.

Picard, M., Wallace, D. C., and Burelle, Y. (2016). The rise of mitochondria in medicine. Mitochondrion 30, 105-116.

Romero-Calvo, I., Ocon, B., Martinez-Moya, P., Suarez, M. D., Zarzuelo, A., Martinez-Augustin, O., and de Medina, F. S.
(2010). Reversible Ponceau staining as a loading control alternative to actin in Western blots. Anal. Biochem. 401, 318-320.

Rossignol, R., Gilkerson, R., Aggeler, R., Yamagata, K., Remington, S. J., and Capaldi, R. A. (2004). Energy substrate modulates mitochondrial structure and oxidative capacity in cancer cells. Cancer Res. 64, 985-993.

Schaefer, W. H., Lawrence, J. W., Loughlin, A. F., Stoffregen, D. A., Mixson, L. A., Dean, D. C., Raab, C. E., Yu, N. X., Lankas, G. R., and Frederick, C. B. (2004). Evaluation of ubiquinone concentration and mitochondrial function relative to cerivastatininduced skeletal myopathy in rats. Toxicol. Appl. Pharmacol. 194, 10-23.

Senior, A. E., Nadanaciva, S., and Weber, J. (2002). The molecular mechanism of ATP synthesis by F1F0-ATP synthase. Biochim. Biophys. Acta 1553, 188-211.

Silva, F. S., Starostina, I. G., Ivanova, V. V., Rizvanov, A. A., Oliveira, P. J., and Pereira, S. P. (2016). Determination of metabolic viability and cell mass using a tandem resazurin/sulforhodamine B assay. Curr. Protoc. Toxicol. 68, 224 1-2 2415.

Smith, R. A., Hartley, R. C., Cocheme, H. M., and Murphy, M. P. (2012). Mitochondrial pharmacology. Trends Pharmacol. Sci. 33, 341-352.

Swiss, R., and Will, Y. (2011). Assessment of mitochondrial toxicity in HepG2 cells cultured in high-glucose- or galactosecontaining media. Curr. Protoc. Toxicol. Chapter 2, Unit 2.20.

Teixeira, J., Oliveira, C., Amorim, R., Cagide, F., Garrido, J., Ribeiro, J. A., Pereira, C. M., Silva, A. F., Andrade, P. B., Oliveira, P. J., et al. (2017). Development of hydroxybenzoicbased platforms as a solution to deliver dietary antioxidants to mitochondria. Sci. Rep. 7, 6842.

Tirmenstein, M. A., Hu, C. X., Gales, T. L., Maleeff, B. E., Narayanan, P. K., Kurali, E., Hart, T. K., Thomas, H. C., and Schwartz, L. W. (2002). Effects of troglitazone on HepG2 viability and mitochondrial function. Toxicol. Sci. 69, 131-138.

Valenti, M. T., Azzarello, G., Balducci, E., Sartore, S., Sandri, M., Manconi, R., Sicari, U., Bari, M., and Vinante, O. (2001). Conditioned medium from MCF-7 cell line induces myofibroblast differentiation, decreased cell proliferation, and increased apoptosis in cultured normal fibroblasts but not in fibroblasts from malignant breast tissue. Histochem. J. 33, 499-509.

Vega-Naredo, I., Loureiro, R., Mesquita, K. A., Barbosa, I. A., Tavares, L. C., Branco, A. F., Erickson, J. R., Holy, J., Perkins, E. L., Carvalho, R. A., et al. (2014). Mitochondrial metabolism directs stemness and differentiation in P19 embryonal carcinoma stem cells. Cell Death Differ. 21, 1560-1574.

Vichai, V., and Kirtikara, K. (2006). Sulforhodamine B colorimetric assay for cytotoxicity screening. Nat. Protoc. 1, 1112-1116.

Wallace, D. C., Fan, W., and Procaccio, V. (2010). Mitochondrial energetics and therapeutics. Annu. Rev. Pathol. 5, 297-348.

Warburg, O., Geissler, A. W., and Lorenz, S. (1967). On growth of cancer cells in media in which glucose is replaced by galactose. Hoppe-Seyler's Z. Physiol. Chem. 348, 1686-1687.

Wilson, L., Yang, Q., Szustakowski, J. D., Gullicksen, P. S., and Halse, R. (2007). Pyruvate induces mitochondrial biogenesis by a PGC-1 alpha-independent mechanism. Am. J. Physiol. Cell Physiol. 292, C1599-C1605. 